\title{
Kajian Isu Pemekaran di Kota Medan: Tinjauan berdasarkan Kondisi Ketimpangan Wilayah
}

\author{
Cynthia Mutiara Pasaribu ${ }^{1}$ \\ Jurusan Perencanaan Wilayah dan Kota \\ Fakultas Teknik, Universitas Diponegoro, Semarang, Indonesia
}

Artikel Masuk : 21 September 2015

Artikel Diterima : 22 Oktober 2015

Tersedia Online : 30 Desember 2015

\begin{abstract}
Abstrak: Ketimpangan pembangunan antara kawasan utara dan kawasan selatan di Kota Medan menjadi sebuah permasalahan yang memunculkan isu pemekaran keempat kecamatan di bagian utara Kota Medan. Tujuan penelitian adalah untuk menganalisis kondisi ketimpangan ekonomi, sosial kependudukan dan pelayanan infrastruktur di Kota Medan terkait kemunculan isu pemekaran di Kota Medan bagian utara. Analisis yang akan digunakan adalah analisis statistik deskriptif menggunakan skoring, analisis korelasi, analisis crosstab serta verifikasi hasil analisis statistik menggunakan wawancara. Analisis statistik deskriptif menghasilkan indeks ekonomi wilayah, sosial kependudukan dan pelayanan infrastruktur untuk setiap kecamatan di Kota Medan yang menjelaskan perbedaan pembangunan. Hasil analisis korelasi menunjukkan bahwa ada hubungan antara kondisi ketimpangan dan kemunculan isu pemekaran. Pada keempat kecamatan yang mengalami isu pemekaran, yaitu Kecamatan Medan Labuhan, Medan Marelan, Medan Belawan, dan Medan Deli mengalami ketimpangan infrastruktur yang kondisinya semakin buruk, jika dibandingkan ketimpangan pada aspek ekonomi dan sosial kependudukan. Hasil analisis crosstab menunjukkan bahwa variabel sarana pendidikan (SMA), kepadatan penduduk, dan tenaga kerja menjadi variabel yang menunjukkan kondisi ketimpangan secara signifikan. Kondisi ini menunjukkan bahwa ketersediaan infrastruktur suatu wilayah mempengaruhi tingkat ketimpangan wilayah karena menunjukkan kemampuan perkembangan suatu wilayah.
\end{abstract}

Kata Kunci: ekonomi wilayah, ketimpangan wilayah, pelayanan infrastruktur, pemekaran wilayah, sosial kependudukan

\begin{abstract}
Development disparity between the northern and southern parts of Medan raises segregation demand for four sub-districts in the northern side. This study purposes to analyze the gap condition in economic, social demography, and infrastructure services associated with the demand. The analyses cover several methods, i.e. descriptive statistics, correlation, and crosstab analyses, and verify the statistical analysis results by using interview method. The correlation analysis shows that there is a correlation between the disparity and segregation issues. The four sub-districts which have segregation issue are Medan Labuhan, Medan Marelan, Medan Belawan, and Medan Deli. They experience worse infrastructure disparity than the economic and social ones. The crosstab analysis shows that the education facilities especially senior high school level, population density, and labor variables have
\end{abstract}

\footnotetext{
${ }^{1}$ Korespondensi Penulis: Jurusan Perencanaan Wilayah dan Kota, Fakultas Teknik, Universitas Diponegoro, Semarang Email: cynthia.pasaribu@ymail.com
} 
contributed significantly to the regional disparity. It indicates that the availability of infrastructure is associated with regional segregation because it reflects the regional growth performance.

Keywords: regional economy, regional disparities, infrastructure service, regional segregation, social demography

\section{Pendahuluan}

Pembangunan berkaitan erat dengan kondisi kesejahteraan masyarakat. Selain bertujuan untuk menciptakan pertumbuhan yang setinggi-tingginya, pembangunan harus pula berupaya untuk menghapus dan mengurangi tingkat kemiskinan, ketimpangan pendapatan, dan tingkat pengganguran (Todaro, 2003). Pembangunan seharusnya menciptakan kesejahteraan bagi semua penduduk, walaupun wajar jika terjadi pemusatan pada wilayah tertentu. Namun, pemusatan seharusnya dapat memberikan efek yang positif bagi wilayah sekitarnya sehingga tidak memunculkan ketimpangan interwilayah. Kondisi ketimpangan sering dilihat dari aspek ekonomi. Selain dari kegiatan perekonomian, ketimpangan akan terlihat dari kondisi fisik daerah seperti kondisi jalan, ketersediaan listrik, telekomunikasi, kondisi permukiman masyarakat. Ketimpangan wilayah pada dasarnya disebabkan adanya perbedaan kandungan sumber daya alam dan perbedaaan kondisi demografi (Mopangga, 2011), sumber daya manusia (Rodriguez-Oreggia, 2005; Birthal, Singh, dan Kumar, 2011), dan aksesibilitas (Hu, 2002).

Hasil penelitian Khairunnisa dan Hidayat (2015) mengungkapkan bahwa dalam penyelesaian ketimpangan ekonomi diperlukan kebijakan pemerintah agar dapat berfokus pada sektor unggulan, dominan dan berpotensi tumbuh dengan mengoptimalkan potensi sumber daya yang tersedia. Nurhuda, Muluk, dan Prasetyo (2013) juga mengungkapkan bahwa Pendapatan Asli Daerah (PAD) dan Indeks Pembangunan Manusia (IPM) yang semakin tinggi dan terdistribusi akan meningkatkan pertumbuhan ekonomi sehingga akan menurunkan ketimpangan pembangunan. Pemerintah pusat juga perlu mengalokasikan PDRB secara merata ke seluruh sektor ekonomi sehingga masing-masing sektor dapat berkontribusi untuk meningkatkan pertumbuhan ekonomi (Santosa, 2015). Rokhman (2012) menambahkan bahwa pemerintah juga perlu melakukan pembangunan berorientasi pada pemerataan dan mendorong terciptanya lapangan kerja dimana masyarakat juga didorong untuk dapat menciptakan usahanya sendiri sehingga menambah perekonomian masyarakat. Dalam kasusnya di negara Cina, Demurger (2001) mengungkapkan bahwa transportasi dan prasarana telekomunikasi akan memacu pertumbuhan wilayah dan memecah gap yang memicu ketimpangan wilayah. Serupa dengan Canaleta, Arzoz, dan Garate (2002) serta Birthal, Singh, dan Kumar (2011) bahwa pembangunan infrastruktur mampu mengurangi disparitas antar wilayah di Eropa, dimana pembangunan infrastruktur berkaitan dengan pertumbuhan pendapatan. Namun demikian, masyarakat di wilayah belakang memiliki perekonomian yang kurang baik dan investasi infrastruktur menjadi tantangan tersendiri (Kumar, Singh, \& Anil, 2015). Ini menunjukkan bahwa ketersediaan infrastruktur berperan penting dalam perkembangan suatu wilayah.

Kota Medan merupakan kota di Provinsi Sumatera Utara yang memiliki disparitas pendapatan paling tinggi yakni dengan nilai rata-rata Indeks Williamson 0,5383 (BPS Kota Medan, 2010). Dibandingkan dengan indeks Williamson Kota Makassar yaitu 0,49 (Midadan, 2015), maka ketimpangan di Kota Medan lebih buruk. Pembangunan di selatan Kota Medan lebih diprioritaskan karena adanya pusat-pusat kegiatan pemerintahan, perdagangan dan jasa, permukiman, serta pendidikan. Pada akhirnya ketimpangan antara utara dan selatan di Kota Medan menjadi sebuah permasalahan yang memunculkan isu 
pemekaran untuk keempat kecamatan di bagian utara yaitu, Kecamatan Medan Deli, Kecamatan Medan Labuhan, Kecamatan Medan Marelan dan Kecamatan Medan Belawan yang menimbulkan kondisi kehidupan yang sudah meresahkan masyarakat sehingga muncul wacana untuk memekarkan diri dengan harapan memperoleh kehidupan yang lebih sejahtera. Di samping itu, pembangunan di Kota Medan pada awalnya memang mengalami pengkonsentrasian pada beberapa kecamatan sebagai pusat kegiatan pemerintahan dan perdagangan. Berdasarkan RPJP Kota Medan tahun 2006-2025, dikemukakan bahwa kebijakan pembangunan Kota Medan belum memperhatikan ketimpangan antar wilayah.

Pemekaran di Medan Utara sudah menjadi isu yang berkembang di masyarakat. Beberapa tim kepanitian yang memprakarsai dan menyusun persiapan pemekaran Medan Utara telah dibentuk oleh masyarakat Medan Utara yaitu Tim Rotasi Pemrakarsa Medan Utara, Panitia Panitia Persiapan Pembentukan Pemerintahan Kota Medan Utara (P4KMU), Tim 17 Pemekaran Medan Utara dan Presidium Masyarakat Medan Utara (PMMU). Kondisi ini menimbulkan pertanyaan penelitian apakah ada hubungan antara kondisi ketimpangan pembangunan terkait munculnya isu pemekaran di Kota Medan. Ketimpangan pembangunan dilihat dari aspek ekonomi daerah, sosial kependudukan dan pelayanan infrastruktur. Untuk itu, apakah kondisi ekonomi, sosial kependudukan, dan pelayanan infrastruktur di kecamatan-kecamatan yang berada di bagian utara lebih buruk dibandingkan dengan kecamatan yang berada di bagian selatan Kota Medan? Apakah ada keterkaitan antara kondisi ketimpangan pembangunan dengan kemunculan isu pemekaran? Tujuan penelitian ini adalah menganalisis kondisi ketimpangan pembangunan di Kota Medan terkait dengan kemunculan isu pemekaran Medan Utara. Ruang lingkup wilayah studi penelitian adalah Kota Medan yang terdiri dari 21 kecamatan. Kota Medan memiliki luas $265,10 \mathrm{~km}^{2}$. Peta administrasi wilayah studi tergambar di Gambar 1.

\section{Metode Penelitian}

Metode penelitian yang digunakan dalam penelitian adalah metode deskriptif kuantitatif. Metode kuantitatif adalah penelitian untuk menguji teori-teori tertentu dengan cara meneliti hubungan antar variabel. Variabel tersebut biasanya diukur dengan instrumen-instrumen penelitian sehingga data yang terdiri dari angka-angka dapat dianalisis berdasarkan prosedur-prosedur statistik (Creswell, 2013).

\section{Teknik Pengumpulan Data}

Teknik pengumpulan data yang digunakan dalam penelitian ini yaitu teknik pengumpulan data sekunder dan primer. Data-data yang dikumpulkan dalam penelitian terinci sebagaimana pada input di Gambar 2.

a. Teknik Pengumpulan Data Sekunder. Teknik pengumpulan data sekunder dilakukan dengan survey instansi, kajian literatur, telaah dokumen. Survey instansi dilakukan kepada beberapa instansi, seperti BPS untuk mendapatkan data-data terkait kondisi ekonomi dan sosial kependudukan di Kota Medan.

b. Teknik Pengumpulan Data Primer. Teknik pengumpulan data primer merupakan teknik pengumpulan dimana informasi yang diperoleh berasal dari sumber-sumber primer, yaitu peneliti langsung terjun mencatat kejadian-kejadian di lapangan. Teknik pengumpulan data primer yang digunakan dalam penelitian ini yaitu wawancara dan observasi lapangan. Wawancara ditujukan kepada beberapa pihak, seperti Bappeda Kota Medan untuk mengetahui kondisi ketimpangan di Kota Medan. Sementara itu, observasi lapangan dilakukan untuk melihat kondisi infrastruktur, seperti jalan, air bersih, telekomunikasi, listrik, dan beberapa jenis sarana mencakup sarana kesehatan, pendidikan, perbankan, dan perdagangan di Kota Medan. 


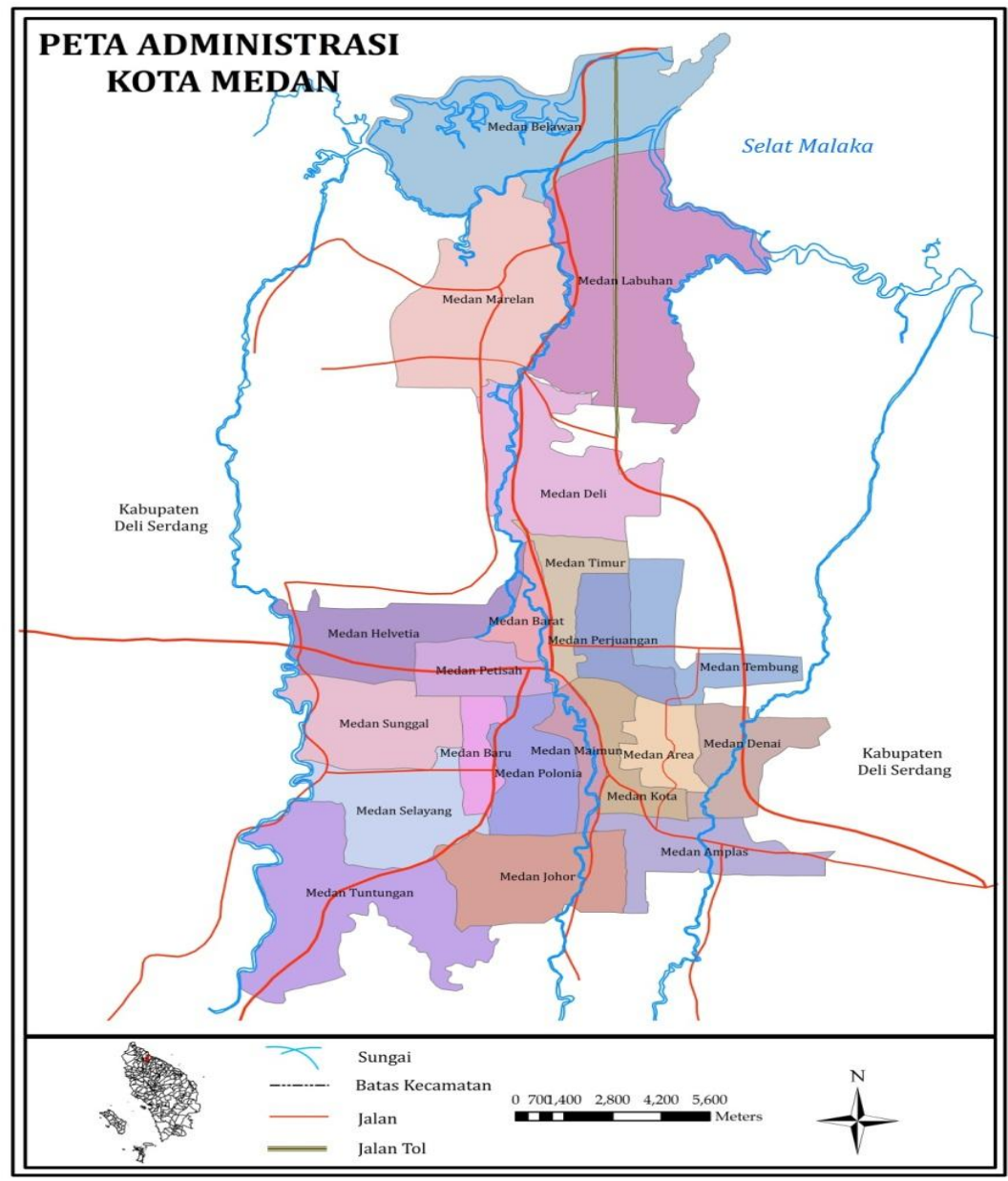

Sumber: Badan Informasi Geografis, 2012

Gambar 1. Wilayah Studi

\section{Teknik Analisis data}

Analisis penelitian menggunakan analisis statistik deskriptif, analisis korelasi, analisis crosstab serta verifikasi dengan wawancara. Masing-masing penggunaan alat analisis terjabarkan pada bagian proses di Gambar 2.

\section{Analisis Statistik Deskriptif}

Statistik deskriptif adalah penyajian data statistik secara numerik, menyajikan ukuran-ukuran numerik yang sangat penting bagi data sampel (Sugianto, 2012). Indeks adalah suatu tipe pengukuran yang merangkum dan meranking beberapa observasi yang spesifik dan menampilkan kembali dalam suatu bentuk dimensi yang lebih umum. Sedangkan skala adalah suatu tipe pengukuran yang terdiri dari beberapa hal yang memiliki struktur yang logis diantaranya (Dwiastuti, 2012). Setiap variabel akan dilakukan penilaian dengan skala sebagai berikut:

$5=$ Sangat baik, nilai $>81 \%$ dari nilai rata-rata/besaran;

$4=$ Baik, nilai $61 \%-80 \%$ dari nilai rata-rata/besaran;

$3=$ Cukup, nilai $41 \%-60 \%$ dari nilai rata-rata/besaran;

$2=$ Buruk, nilai $21 \%-40 \%$ dari nilai rata-rata/besaran; 
$1=$ Sangat Buruk, $<20 \%$ dari nilai rata-rata/besaran .

Penggunaan skor akan dilakukan secara berbeda untuk data tingkat kemiskinan, tingkat pengangguran, migrasi keluar, permukiman kumuh, tenaga kerja:

$5=$ Sangat baik , nilai $<20 \%$ dari nilai rata-rata/besaran;

$4=$ Baik, nilai $21 \%-40 \%$ dari nilai rata-rata/besaran;

$3=$ Cukup, nilai $41 \%-60 \%$ dari nilai rata-rata/besaran;

$2=$ Buruk , nilai $61 \%-80 \%$ dari nilai rata-rata/besaran;

$1=$ Sangat Buruk, $>80 \%$ dari nilai rata-rata/besaran.

Setelah nilai untuk setiap indikator didapatkan maka akan dilakukan penilaian dari hasil skoring untuk bisa menentukan daerah perlu dimekarkan atau belum. Dimana akan dibandingkan nilai seluruh indikator di masing-masing kecamatan dengan nilai terbaik, sehingga didapatkan nilai indeks setiap kecamatan dari rentang 0 - 1.

\section{Analisis Korelasi}

Analisis korelasi adalah studi pembahasan tentang derajat keeratan hubungan antarvariabel yang dinyatakan dengan koefisien korelasi. Hubungan antara variabel bebas dan variabel terikat. Pada penelitian ini variabel bebas adalah kondisi ketimpangan yang digambarkan dengan ekonomi wilayah, sosial kependudukan, dan pelayanan infrastruktur. Sedangkan variabel terikatnya adalah wilayah yang diwacanakan untuk dimekarkan. Data variabel bebas yang merupakan data nominal, maka jenis analisis korelasi yang dilakukan adalah analisis korelasi rank spearman. Besarnya hubungan yang mengukur korelasi spearman disebut koefisien korelasi berpangkat atau korelasi spearman yang dinyatakan dengan lambang $\mathrm{r}_{\mathrm{s}}$. Analisis ini akan menggunakan aplikasi SPSS untuk memudahkan proses pengolahan data.

Ho = Tidak ada hubungan antara kondisi ketimpangan (ekonomi wilayah, sosial kependudukan, dan pelayanan infrastruktur) dengan munculnya isu pemekaran Medan Utara.

$\mathrm{H} 1$ = Adanya hubungan antara kondisi ketimpangan (ekonomi wilayah, sosial kependudukan, dan pelayanan infrastruktur) dan munculnya isu pemekaran Medan Utara

Dimana kriteria pengambilan keputusan adalah (Usman \& Akbar, 2008):

- Jika nilai $r_{s}$ hitung $\leq r_{s}$ tabel, maka $H_{o}$ diterima atau korelasi tidak signifikan.

- Jika nilai $r_{s}$ hitung $\geq r_{s}$ tabel, maka $H_{1}$ diterima dan korelasi signifikan.

\section{Analisis Crosstab}

Metode crosstabs (tabulasi silang) merupakan metode yang menggunakan uji statistik untuk mengidentifikasikan dan mengetahui korelasi antara dua variabel. Statistik Crosstab digunakan untuk mengetahui hubungan/distribusi respon antara variabel data dalam bentuk baris dan kolom. 


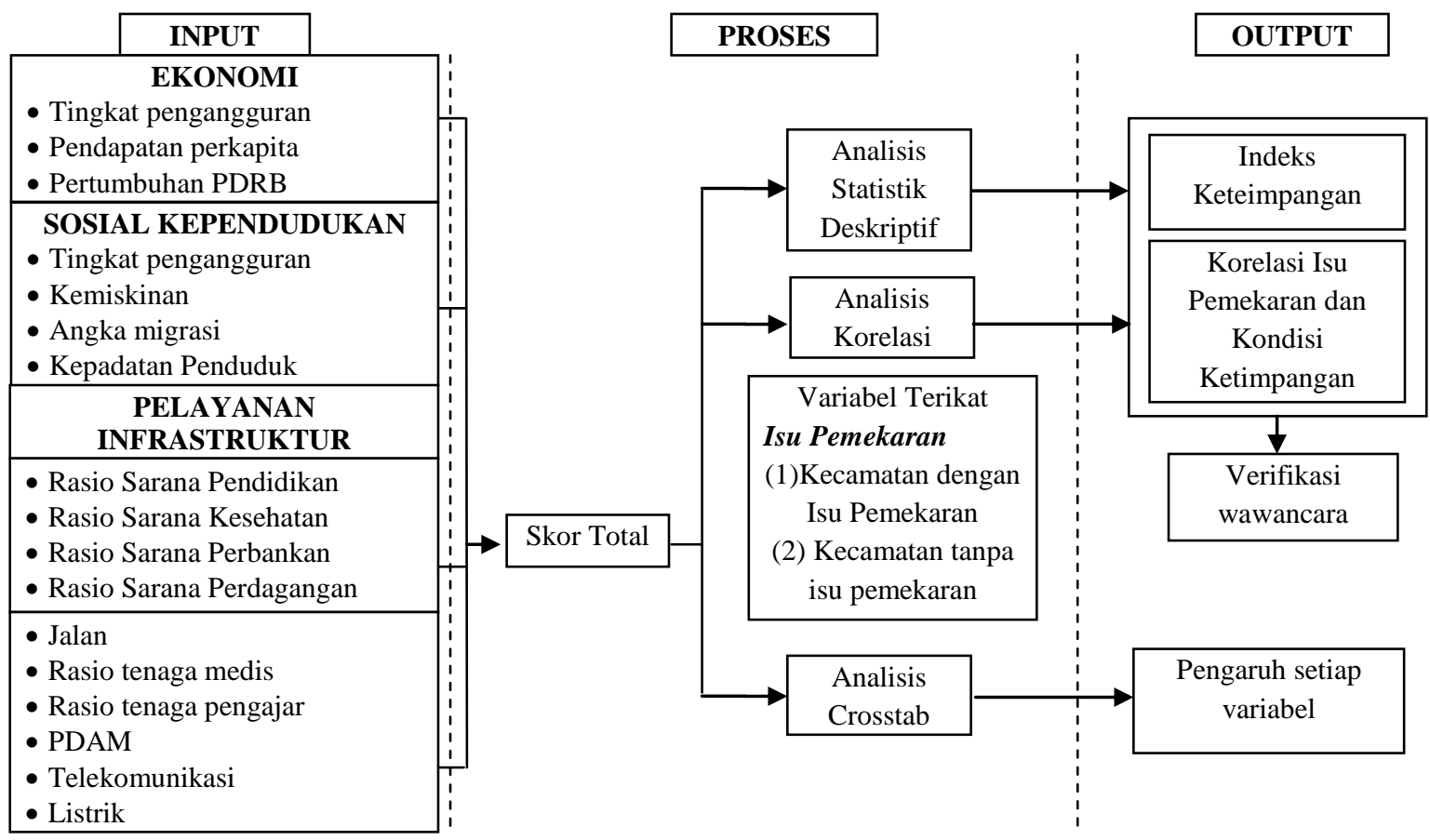

Gambar 2. Kerangka Analisis Penelitian

\section{Hasil Penelitian}

\section{Kondisi Ketimpangan di Kota Medan}

Analisis kondisi ketimpangan mencakup aspek ekonomi, sosial kependudukan, dan pelayanan infrastruktur. Masing-masing kondisi ketimpangan memiliki kategori penilaian indeks:

$$
\begin{array}{ll}
0-0,33 & =\text { Buruk; } \\
0,34-0,66 & =\text { Sedang; } \\
0,67-1 & =\text { Baik. }
\end{array}
$$

Ketimpangan pada aspek ekonomi mencakup variabel PDRB, pendapatan perkapita, dan jumlah penduduk yang bekerja di sektor primer. Ketimpangan pada aspek kependudukan mencakup variabel kemiskinan, pengangguran, kepadatan penduduk, migrasi penduduk. Ketimpangan aspek infrastruktur meliputi variabel sarana pendidikan, sarana kesehatan, sarana perbankan, sarana perdagangan, air bersih, listrik, dan permukiman kumuh. Tabel 1 menunjukkan indeks ketimpangan aspek ekonomi, sosial kependudukan, dan infrastruktur di Kota Medan yang dikalkulasi berdasarkan masingmasing variabel dari masing-masing aspek. Tabel 1 juga menunjukkan nilai indeks ketimpangan total yang di rata-rata dari masing-masing aspek.

Hasil indeks ketimpangan total menunjukkan bahwa sebanyak 17 kecamatan (81\%) di Kota Medan tergolong baik yang berarti tidak menunjukkan adanya fenomena ketimpangan wilayah. Namun demikian, ada 4 kecamatan (19\%) yang tergolong sedang atau mengalami ketimpangan wilayah berlevel sedang, seperti di Kecamatan Medan Deli, Medan Labuhan, Medan Marelan, dan Medan Belawan. Ini dikarenakan, jika ditelusur lebih lanjut, dua kecamatan, yaitu Medan Labuhan dan Medan Marelan ternyata mengalami ketimpangan kondisi ekonomi berlevel buruk. sementara itu, secara aspek sosial 
kependudukan kedua kecamatan tersebut mengalami ketimpangan kondisi berlevel sedang dan aspek infrastruktur menunjukkan kategori baik dan sedang.

Tabel 1.Indeks Ketimpangan Aspek Ekonomi, Sosial Kependudukan, Infrastruktur, dan Ketimpangan Total di Kota Medan

\begin{tabular}{|c|c|c|c|c|c|c|c|c|c|}
\hline \multirow[t]{2}{*}{ No } & \multirow[t]{2}{*}{ Kecamatan } & \multicolumn{2}{|c|}{$\begin{array}{l}\text { Ketimpangan } \\
\text { Aspek Ekonomi }\end{array}$} & \multicolumn{2}{|c|}{$\begin{array}{c}\text { Ketimpangan } \\
\text { Aspek Sosial } \\
\text { Kependudukan }\end{array}$} & \multicolumn{2}{|c|}{$\begin{array}{c}\text { Ketimpangan } \\
\text { Aspek } \\
\text { Infrastruktur }\end{array}$} & \multicolumn{2}{|c|}{$\begin{array}{c}\text { Ketimpangan } \\
\text { Total }\end{array}$} \\
\hline & & Indeks & Kategori & Indeks & Kategori & Indeks & Kategori & Indeks & Kategori \\
\hline 1. & $\begin{array}{l}\text { Medan } \\
\text { Tuntungan }\end{array}$ & 0,43 & Sedang & 0,53 & Sedang & 0,83 & Baik & 0,73 & Baik \\
\hline 2. & Medan Johor & 0,37 & Sedang & 0,60 & Sedang & 0,81 & Baik & 0,71 & Baik \\
\hline 3. & $\begin{array}{l}\text { Medan } \\
\text { Amplas }\end{array}$ & 0,83 & Baik & 0,47 & Sedang & 0,71 & Baik & 0,72 & Baik \\
\hline 4. & Medan Denai & 0,50 & Sedang & 0,60 & Sedang & 0,70 & Baik & 0,67 & Baik \\
\hline 5. & Medan Area & 0,63 & Sedang & 0,63 & Sedang & 0,83 & Baik & 0,79 & Baik \\
\hline 6. & Medan Kota & 0,87 & Baik & 0,67 & Baik & 0,90 & Baik & 0,88 & Baik \\
\hline 7. & $\begin{array}{l}\text { Medan } \\
\text { Maimun }\end{array}$ & 0,87 & Baik & 0,63 & Sedang & 0,79 & Baik & 0,81 & Baik \\
\hline 8. & $\begin{array}{l}\text { Medan } \\
\text { Polonia }\end{array}$ & 1,00 & Baik & 0,63 & Sedang & 0,78 & Baik & 0,81 & Baik \\
\hline 9. & Medan Baru & 0,87 & Baik & 0,73 & Baik & 0,80 & Baik & 0,83 & Baik \\
\hline 10. & $\begin{array}{l}\text { Medan } \\
\text { Selayang }\end{array}$ & 0,37 & Sedang & 0,53 & Sedang & 0,84 & Baik & 0,72 & Baik \\
\hline 11. & $\begin{array}{l}\text { Medan } \\
\text { Sunggal }\end{array}$ & 0,50 & Sedang & 0,60 & Sedang & 0,80 & Baik & 0,73 & Baik \\
\hline 12. & $\begin{array}{l}\text { Medan } \\
\text { Helvetia }\end{array}$ & 0,73 & Baik & 0,63 & Sedang & 0,74 & Baik & 0,75 & Baik \\
\hline 13. & $\begin{array}{l}\text { Medan } \\
\text { Petisah }\end{array}$ & 0,93 & Baik & 0,70 & Baik & 0,87 & Baik & 0,87 & Baik \\
\hline 14. & Medan Barat & 0,60 & Sedang & 0,67 & Baik & 0,77 & Baik & 0,74 & Baik \\
\hline 15. & $\begin{array}{l}\text { Medan } \\
\text { Timur }\end{array}$ & 0,90 & Baik & 0,60 & Sedang & 0,82 & Baik & 0,82 & Baik \\
\hline 16. & $\begin{array}{l}\text { Medan } \\
\text { Perjuangan }\end{array}$ & 0,47 & Sedang & 0,57 & Sedang & 0,74 & Baik & 0,68 & Baik \\
\hline 17. & $\begin{array}{l}\text { Medan } \\
\text { Tembung }\end{array}$ & 0,63 & Sedang & 0,60 & Sedang & 0,82 & Baik & 0,77 & Baik \\
\hline 18. & Medan Deli & 0,87 & Baik & 0,53 & Sedang & 0,62 & Sedang & 0,66 & Sedang \\
\hline 19. & $\begin{array}{l}\text { Medan } \\
\text { Labuhan }\end{array}$ & 0,20 & Buruk & 0,47 & Sedang & 0,71 & Baik & 0,57 & Sedang \\
\hline 20. & $\begin{array}{l}\text { Medan } \\
\text { Marelan }\end{array}$ & 0,33 & Buruk & 0,40 & Sedang & 0,59 & Sedang & 0,51 & Sedang \\
\hline 21. & $\begin{array}{l}\text { Medan } \\
\text { Belawan }\end{array}$ & 0,87 & Baik & 0,40 & Sedang & 0,62 & Sedang & 0,64 & Sedang \\
\hline
\end{tabular}

Peta- peta berikut mengambarkan persebaran indeks ketimpangan ekonomi (Gambar 3a), sosial kependudukan (Gambar 3b), pelayanan infrastruktur (Gambar 3c) dan ketimpangan total (Gambar 3d) di Kota Medan. 


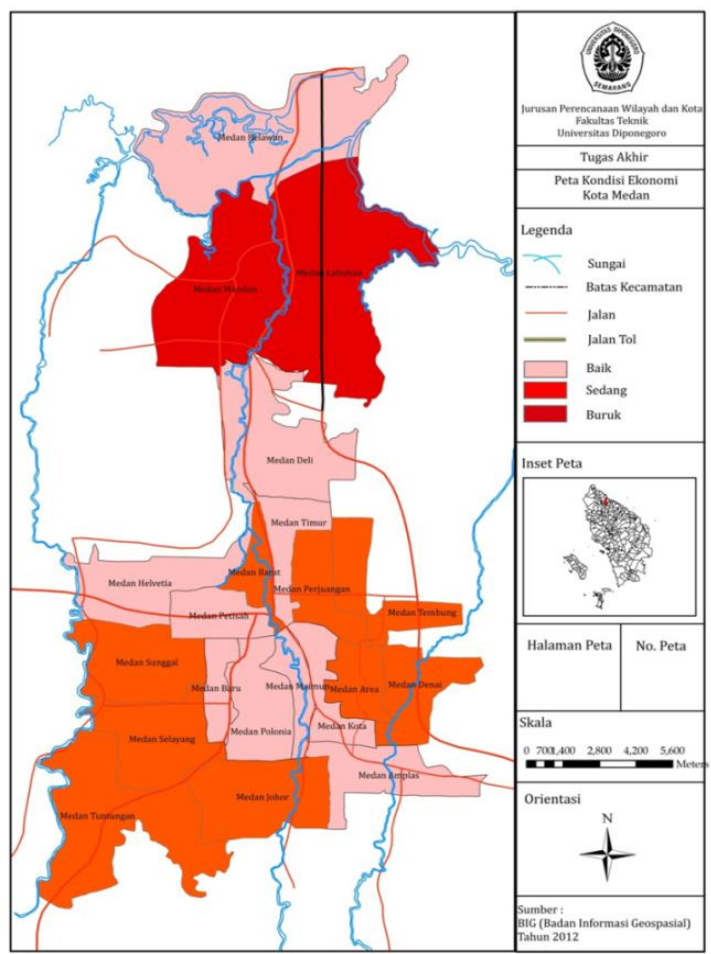

(a)

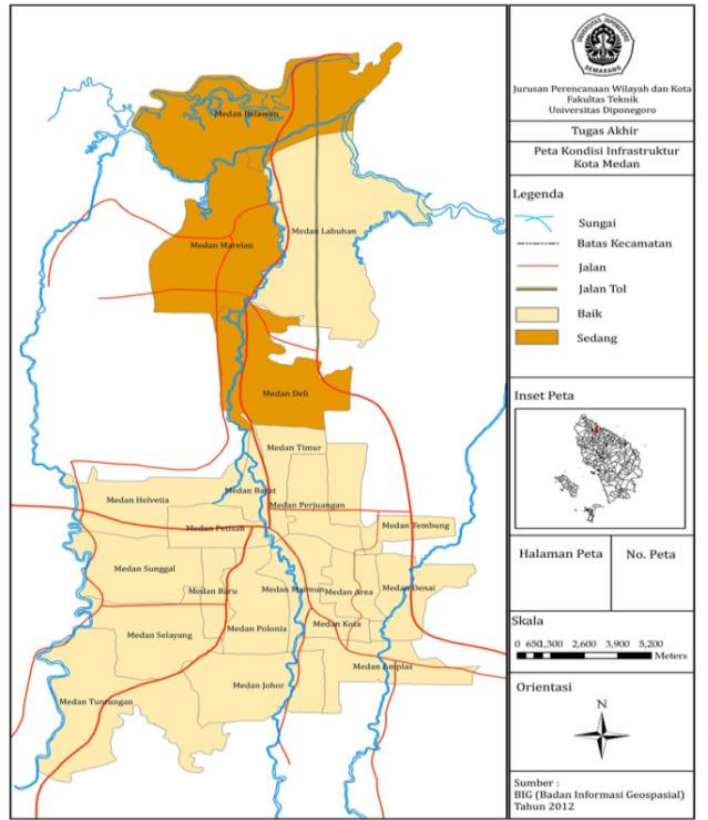

(c)

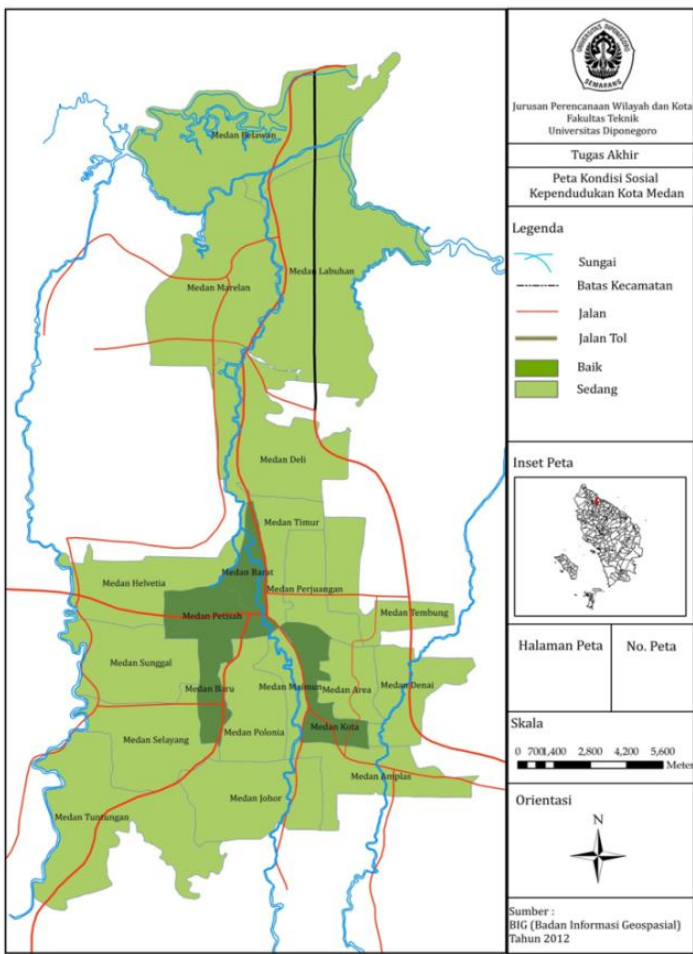

(b)

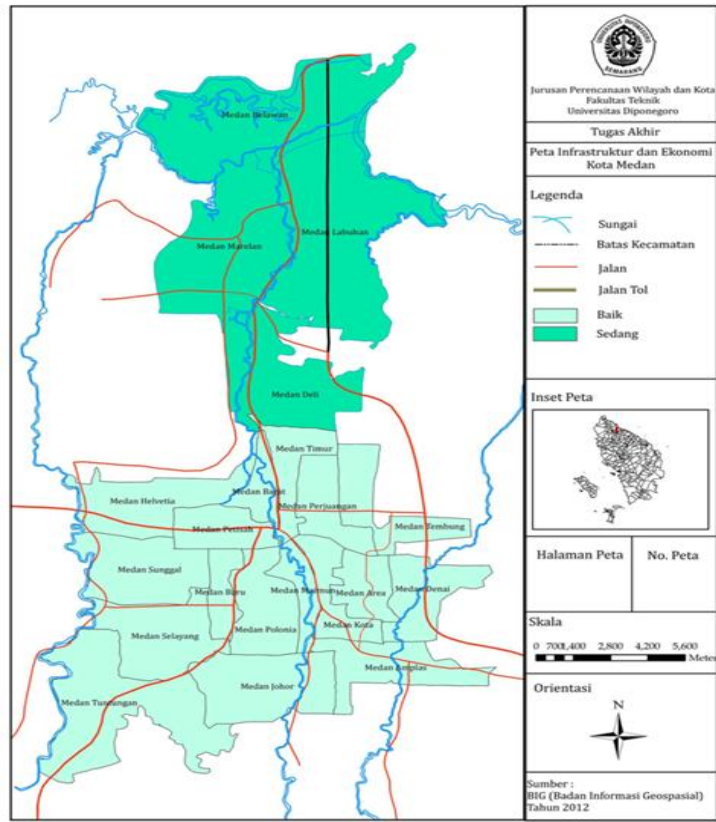

(d)

\section{Gambar 3. Peta a) Indeks Ketimpangan Ekonomi; b) Indeks Ketimpangan Sosial Kependudukan;} c) Indeks Ketimpangan Infrastruktur; c) Indeks Ketimpangan Total 


\section{Hubungan Kondisi Ketimpangan dan Isu Pemekaran}

Jika Nilai $r_{s}$ hitung $\geq r_{s}$ tabel, maka $H_{1}$ diterima dan korelasi signifikan. Nilai koefisien korelasi spearman tabel dengan tingkat kesalahan $0,05, \mathrm{n}=21$ adalah 0,435 , sehingga: Jika nilai $=r_{s}$ hitung $\geq r_{s}$ tabel, maka $H_{1}$ diterima dan korelasi signifikan $=0,681 \geq 0.435$, sehingga ada hubungan antara kondisi ketimpangan infrastruktur, sosial kependudukan dan ekonomi dengan kemunculan wacana isu pemekaran wilayah di Kota Medan. Berdasarkan hasil analisis korelasi, terdapat kaitan antara kondisi ketimpangan dengan kemunculan isu pemekaran Medan Utara. Namun, jika lebih diteliti setiap variabel akan diketahui bahwa kondisi ketimpangan yang berdampak besar terhadap kemunculan isu pemekaran adalah variabel infrastruktur daerah dan variabel sosial kependudukan. Sedangkan variabel ekonomi belum bisa menjadi penjelas kemunculan isu pemekaran Medan Utara secara signifikan. Berdasarkan analisis korelasi didapatkan bahwa terdapat kondisi ketimpangan yang berkaitan dengan kemunculan isu pemekaran Medan Utara. Gambar 4 menunjukkan pengaruh setiap variabel terhadap isu ketimpangan di Medan Utara. Dari grafik di Gambar 4 terlihat bahwa kecamatan yang memiliki isu pemekaran terjadi ketimpangan kondisi infrastruktur yang cukup signifikan, jika dibandingkan dengan ketimpangan dari aspek ekonomi dan sosial kependudukan. Hal ini sesuai jika dikaitkan dengan pendapat Demurger (2001), Canaleta, Arzoz, dan Garate (2002), dan Birthal, Singh, dan Kumar (2011) bahwa infrastruktur berkaitan dengan ketimpangan wilayah. Bahkan, pada kasus di Kota Medan bahwa ketimpangan wilayah dapat memicu pemekaran wilayah.

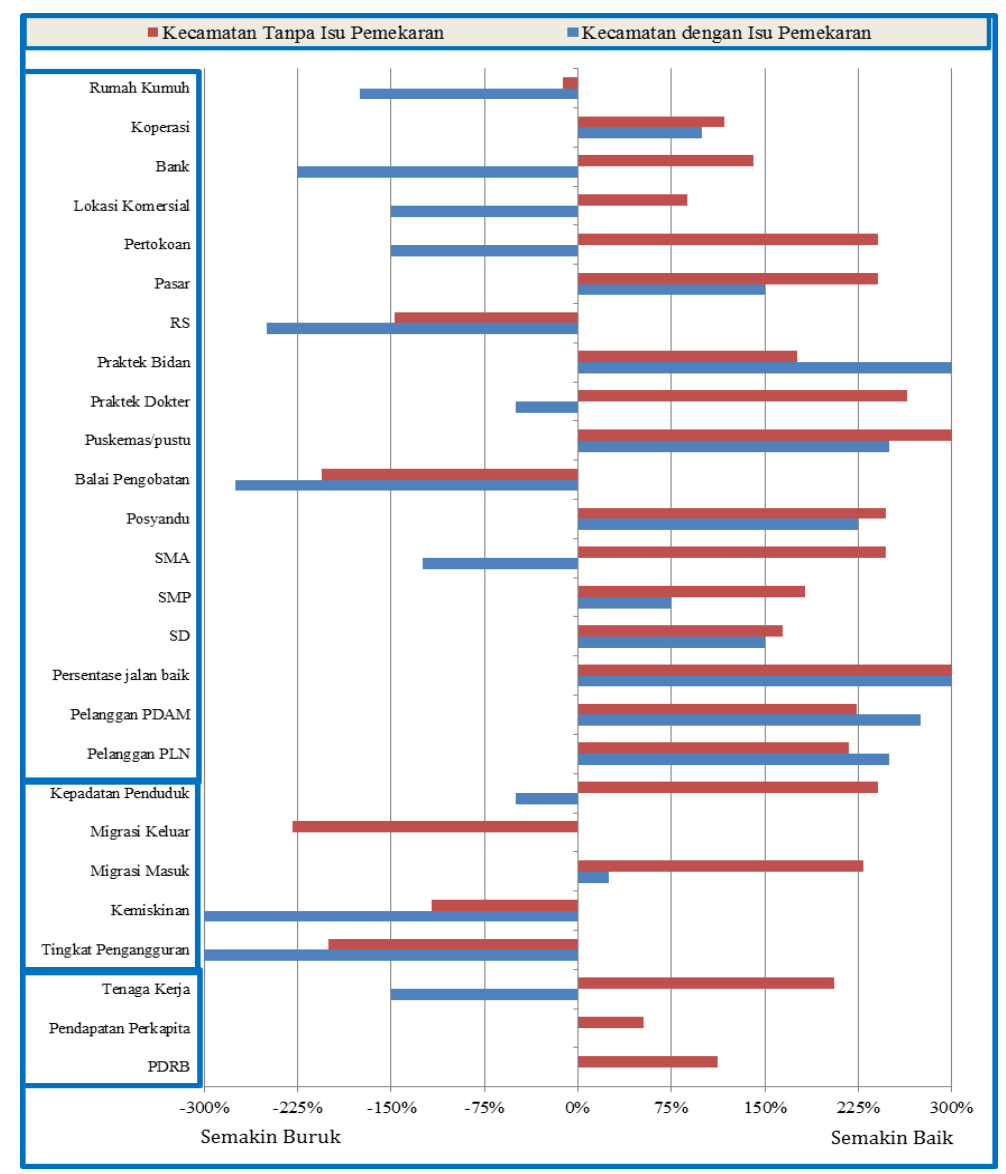

Gambar 5. Persentase Pengaruh Variabel 


\section{Tanggapan Pemerintah}

Berdasarkan dengan hasil wawancara, pihak Pemerintah Kota Medan menyatakan bahwa kondisi ketimpangan pembangunan memang terjadi di Kota Medan, dimana daerah di bagian utara memiliki pembangunan yang tidak begitu pesat dibandingkan dengan daerah di bagian selatan. Kondisi ketimpangan yang sangat terlihat adalah dari segi infrastruktur, dinyatakan memang banyak infrastruktur di kecamatan di bagian utara yang lebih minim. Selain itu, Sumber Daya Manusia (SDM) yang ada di Medan Utara dinyatakan kurang memiliki kemampuan dan keahlian sehingga dapat bersaing. Sehingga banyak ditemui masyarakat miskin di daerah ini. Namun, hal ini sudah mulai disadari oleh Pemerintah Kota Medan dan berusaha untuk memperbaikinya dengan disusunnya rencana daerah yang mendukung pembangunan di Medan Utara. Dana pembangunan juga sudah di tingkatkan agar pembangunan lebih merata.

Wawancara dengan pihak Bappeda Kota Medan, menyatakan bahwa kondisi ketimpangan secara infrastruktur memang ada. Namun Bappeda berusaha untuk meningkatkan kondisi pelayanan infrastruktur dengan menyusun rencana pembangunan yaitu membuat pusat pelayanan kota di bagian utara yaitu di Medan Labuhan. Pusat pelayanan kota yang baru ini diharapkan bisa menjadi solusi pembangunan di Medan Utara. Pusat pelayanan kota ini berfungsi sebagai pusat kegiatan perdagangan dan jasa regional, pusat pelayanan transportasi, kegiatan sosial budaya, pusat kegiatan industri serta pusat pertahanan nasional.

Kondisi dari alam maupun SDM relatif unik untuk kecamatan di bagian utara Kota Medan. Dari segi SDA, kecamatan di wilayah utara berbatasan dengan laut sehingga rawan akan bencana banjir rob, banyaknya sungai-sungai yang tempat tinggal maupun sarana transportasi masyarakat nelayan, lahan yang berdekatan dengan laut mengindikasikan kesuburan lahan yang tidak begitu baik. Selain itu, hal lain yang membedakan dengan kecamatan yang berada di selatan adalah penduduk sudah memiliki keahliaan tertentu untuk menciptakan lapangan pekerjaan sendiri mulai dari industri membuat kue oleh-oleh khas Kota Medan, pembuatan perabotan rumah tangga, pengolahan kopi, pembuatan sepatu, dan lainnya. Hasil analisis korelasi memperkuat bahwa terdapat korelasi antara kondisi ketimpangan dengan kemunculan isu pemekaran Medan Utara. Kondisi yang relatif kurang baik dari segi ekonomi, pelayanan infrastruktur maupun sosial kependudukan di keempat kecamatan yang tersebar di bagian utara Kota Medan mempengaruhi kemunculan isu pemekaran.

\section{Kesimpulan dan Rekomendasi}

\section{Kesimpulan}

Pada kasus keempat kecamatan di Kota Medan yang memiliki isu pemekaran wilayah, yaitu di Kecamatan Medan Labuhan, Medan Marelan, Medan Belawan, dan Medan Deli menunjukkan bahwa keempat kecamatan memiliki ketimpangan wilayah berlevel sedang. Adapun kontribusi terbesar berasal dari indeks ketimpangan kondisi infrastruktur. Hal ini menunjukkan bahwa kondisi infrastruktur sangat berpengaruh terhadap ketimpangan wilayah karena menyangkut kemampuan suatu wilayah untuk berkembang. Kondisi ini diperkuat dengan hasil wawancara dengan pemerintah Kota Medan bahwa kecamatan di bagian utara Kota Medan memang memiliki infrastruktur yang terbatas. Namun demikian, secara komprehensif bahwa kondisi yang relatif kurang baik dari segi ekonomi, pelayanan infrastruktur maupun sosial kependudukan di keempat kecamatan yang tersebar di bagian utara Kota Medan mempengaruhi kemunculan isu pemekaran. 


\section{Rekomendasi}

- Dari segi ekonomi dengan memberikan perhatian khusus pada rencana pembangungan pusat pelayanan kota yang direncanakan dibangun di Medan Labuhan agar pusat pelayanan kota yang baru ini dapat berfungsi dan memberikan manfaat bagi kegiatan perekonomian masyarakat serta mendistribusikan pusat-pusat kegiatan di Kota Medan lebih merata.

- Dari segi sosial kependudukan dengan meningkatkan keahlian bagi kaum muda untuk bias berkontribusi dalam peningkatan ekonomi daerah dengan melalui pembinaan secara formal maupun informal.

- Dari segi infrastruktur melalui penyediaan fasilitas dan bantuan agar masyarakat yang bekerja di sektor primer dapat bekerja dan kebutuhan hidup mereka tetap bisa tercukupi; penyediaan sarana-sarana dalam memenuhi kebutuhan masyarakat seperti sarana perdagangan dan perbankan untuk memudahkan masyarakat melakukan kegiatan perekonomian oleh pemerintah; dan prioritasi program revitalisasi permukiman kumuh yang tersebar di seluruh kecamatan Kota Medan.

\section{Daftar Pustaka}

Birthal, P. S., Singh, H., \& Kumar, S. (2011). Agriculture, economic growth and regional disparities in India. Journal of International Development, 23, 119-131. doi:10.1002/jid.1606.

BPS Kota Medan. (2010). Kota Medan dalam angka 2010. Medan: BPS Kota Medan.

Canaleta, C. G., Arzoz, P. P., \& Garate, M. R. (2002). Structural change, infrastructure and convergence in the regions of the European Union. European Urban and regional Studies, 9(2), 115-135, doi:10.1177/096977640200900202.

Creswell, J. (2013). Research design: Pendekatan kualitatif, kuantitatif dan mixed. Yogyakarta: Pustaka Pelajar.

Demurger, S. (2001). Infrastructure development and economic growth: An explanaton for regional disparities in China? Journal of Comparative Economics, 29(1), 95-117. doi:10.1006/jcec.2000.1693.

Dwiastuti, R. (2012). Metode penelitian sosial: Rancangan instrumen penelitian. Modul Kuliah Fakultas Agrikultur Universitas Brawijaya, Malang International Daylight Monitoring Programme. Retrieved from http://idmp.entpe.fr/.

Hu, D. (2002). Trade, rural-urban migration, and regional income disparity in developing countries: A spatial general equilibrium model inspired by the case of China. Regional Science and Urban Economics, 32(3), 311-338. doi:10.1016/S0166-0462(01)00075-8.

Khairunnisa, A., \& Hidayat, P. (2015). Analisis disparitas pembangunan ekonomi antar kecamatan di Kota Medan. Jurnal Ekonomi dan Keuangan, 3(6), 448-463.

Kumar, M., Singh, P., \& Anil. (2015). Regional disparity in the level of ingrastructural development in Haryana. The International Journal of Sciences and Humanities Invention, 2(10), 1663-1668. doi:10.18535/ijsshi/v2i10.07.

Midadan, M. (2015). Dana perimbangan dan alokasi belanja modal serta implikasinya terhadap ketimpangan daerah di Provinsi Sulawesi Selatan (Unpublished undergraduate thesis). Program Ilmu Ekonomi, Fakultas Ekonomi dan Bisnis. Universitas Hasanuddin, Makasar).

Mopangga, H. (2011). Analisis ketimpangan pembangunan dan pertumbuhan ekonomi di Provinsi Gorontalo. Trikonomika, 10(1), 40-51.

Nurhuda, R., Muluk, M. R. K., \& Prasetyo, W. Y. (2013). Analisis ketimpangan pembangunan (Studi Provinsi Jawa Timur tahun 2005-2011). Jurnal Administrasi Publik (JAP), 1(4), 110-119.

Rokhman, W. (2012). Analisis disparitas pendapatan kabupaten/ kota di Provinsi Jawa Tengah tahun 20072009. Economics Development Analysis Journal, 1(1). doi:10.15294/edaj.v1i1.327.

Rondriguez-Oreggia, E. (2005). Regional disparities and determinants of growth in Mexico. The Annals of Regional Science, 39, 207-220. doi:10.1007/s00168-004-0218-5. 


\section{Kajian Isu Pemekaran di Kota Medan: Tinjauan berdasarkan Kondisi Ketimpangan Wilayah}

Santosa, S. H. (2015). Disparitas pertumbuhan ekonomi dan pembangunan ekonomi wilayah di Satuan Wilayah Pembangunan IV Propinsi Jawa Timur. Media Trend, 10(2), 116-128.

Sugianto, M. (2012). Mengolah data bisnis dengan SPSS 20. Jakarta: PT. Elex Media Komputindo.

Todaro, M. P., \& dan Smith, S. C. (2003). Pembangunan ekonomi dunia ketiga (Wisnu C. Kristiaji, Trans.). Jakarta: PT. Gelora Aksara Pratama, Erlangga.

Usman, H., \& Akbar, P.S. (2008). Pengantar statistika (Edisi kedua). Jakarta: Bumi Aksara. 